\title{
Exploiting mitochondrial and metabolic homeostasis as a vulnerability in NF1 deficient cells
}

\author{
Robert J. Allaway', Matthew D. Wood ${ }^{2,8}$, Sondra L. Downey ${ }^{2}$, Stephanie J. Bouley ${ }^{1}$, \\ Nicole A. Traphagen ${ }^{1}$, Jason D. Wells ${ }^{3}$, Jaya Batra ${ }^{2,9}$, Sir Norman Melancon ${ }^{2,10}$, \\ Carol Ringelberg ${ }^{1,4}$, William Seibel ${ }^{5}$, Nancy Ratner ${ }^{6}$ and Yolanda Sanchez ${ }^{1,7}$ \\ ${ }^{1}$ Department of Molecular and Systems Biology, Geisel School of Medicine, Dartmouth College, Hanover, NH 03755, USA \\ ${ }^{2}$ Department of Pharmacology and Toxicology, Geisel School of Medicine, Dartmouth College, Hanover, NH 03755, USA \\ ${ }^{3}$ Department of Epidemiology, Geisel School of Medicine, Dartmouth College, Hanover, NH 03755, USA \\ ${ }^{4}$ Bioinformatics Shared Resource, Norris Cotton Cancer Center, Dartmouth-Hitchcock Medical Center, Lebanon, NH 03756, USA \\ ${ }^{5}$ Division of Oncology, Cincinnati Children's Hospital Medical Center, Cancer and Blood Diseases Institute, Cincinnati, $\mathrm{OH}$ \\ 45229, USA \\ ${ }^{6}$ Division of Experimental Hematology and Cancer Biology, Cincinnati Children's Hospital Medical Center, Cancer and Blood \\ Diseases Institute, Cincinnati, OH 45229, USA \\ ${ }^{7}$ Norris Cotton Cancer Center, Dartmouth-Hitchcock Medical Center, Lebanon, NH 03756, USA \\ ${ }^{8}$ Current address: Department of Pathology, University of California San Francisco, San Francisco, CA 94143, USA \\ ${ }^{9}$ Current address: Icahn School of Medicine at Mount Sinai, New York, NY 10029, USA \\ ${ }^{10}$ Current address: Vanderbilt School of Medicine, Nashville, TN 37232, USA \\ Correspondence to: Yolanda Sanchez, email: yolanda.sanchez@dartmouth.edu \\ Keywords: neurofibromin 1; RAS; synthetic lethal; mitochondria; proteostasis \\ Received: October 19,2016 Accepted: July 09, 2017 Epub: July 18, 2017 Published: March 23, 2018
}

Copyright: Allaway et al. This is an open-access article distributed under the terms of the Creative Commons Attribution License 3.0 (CC BY 3.0), which permits unrestricted use, distribution, and reproduction in any medium, provided the original author and source are credited.

\section{ABSTRACT}

Neurofibromatosis type 1 is a disease caused by mutation of neurofibromin 1 (NF1), loss of which results in hyperactive Ras signaling and a concomitant increase in cell proliferation and survival. Patients with neurofibromatosis type 1 frequently develop tumors such as plexiform neurofibromas and malignant peripheral nerve sheath tumors. Mutation of NF1 or loss of the NF1 protein is also observed in glioblastoma, lung adenocarcinoma, and ovarian cancer among other sporadic cancers. A therapy that selectively targets NF1 deficient tumors would substantially advance our ability to treat these malignancies.

To address the need for these therapeutics, we developed and conducted a synthetic lethality screen to discover molecules that target yeast lacking the homolog of NF1, IRA2. One of the lead candidates that was observed to be synthetic lethal with ira2 2 yeast is Y100. Here, we describe the mechanisms by which Y100 targets ira2 2 yeast and NF1-deficient tumor cells. Y100 treatment disrupted proteostasis, metabolic homeostasis, and induced the formation of mitochondrial superoxide in NF1-deficient cancer cells. Previous studies also indicate that NF1/Ras-dysregulated tumors may be sensitive to modulators of oxidative and ER stress. We hypothesize that the use of Y100 and molecules with related mechanisms of action represent a feasible therapeutic strategy for targeting NF1 deficient cells.

\section{INTRODUCTION}

The development of targeted cancer therapeutics enables clinicians to target malignancies with unique oncogenomic characteristics. However, in tumors driven by loss-of-function of a tumor suppressor, direct targeting of the driver mutation is not feasible. One example of this scenario are tumors with genomic mutation of neurofibromin $1(N F 1)$ or decreased expression of its gene product (NF1). Therefore, therapeutic studies have mainly 
focused on targeting loss of NF1 indirectly, focusing on the fact that NF1 serves as a Ras-GTPase activating protein (Ras-GAP). NF1 promotes Ras' intrinsic GTPase activity and facilitates the shift of the Ras protein from an active (Ras-GTP) to an inactive (Ras-GDP) state [1]. Loss of NF1 thus results in increased active Ras, causing a concomitant increase in cellular proliferation, migration, and survival [2-4]. Heterozygous germline mutation of $N F 1$ results in the genetic disease neurofibromatosis type 1 [5]. Patients with neurofibromatosis type 1 can exhibit a variety of symptoms including café-au-lait spots, learning disabilities, and predisposition to tumors such as optic pathway gliomas, plexiform neurofibromas $(\mathrm{PN})$, and malignant peripheral nerve sheath tumors (MPNSTs) $[5,6]$. These tumors generally exhibit biallelic inactivation of $N F 1$ [7]. Mutation of $N F 1$ has also been observed in many sporadic tumor types including lung adenocarcinoma, sporadic MPNSTs, ovarian cancer, and glioblastoma (GBM) [6, 8-11]. The Cancer Genome Atlas (TCGA) studies have demonstrated that $10-23 \%$ of GBMs exhibit deletion, truncation, or missense mutation in $N F 1$, with up to $38 \%$ of mesenchymal GBMs containing $N F 1$ mutations [11-13]. Furthermore, NF1 can be depleted in tumors by posttranscriptional regulatory mechanisms such as miRNA silencing and degradation of the NF1 protein by the proteasome [14-18]. This suggests that a subset of tumors with a wild-type NF1 gene may not express functional NF1 protein.

Recently, progress has been made towards discovering therapeutics for the treatment of PNs and MPNSTs lacking NF1. For example, BRD4 inhibitors have shown efficacy in preclinical models of MPNST [19]. Additionally, inhibitors of the Ras effector protein MEK have been explored in preclinical studies and clinical trials for tumors linked to NF1 loss [20-25]. Finally, tumor metabolism (mTOR signaling) has been explored as a targetable mechanism in NF1-deficient tumor types using the small molecules everolimus and sirolimus [26-28]. However, these approaches have had mixed clinical success (mTOR inhibitors), still need to be demonstrated as efficacious in humans (BRD4 inhibitors), or are in the process of being evaluated in humans (MEK inhibitors), suggesting that there is still a need for novel therapeutics that target these tumors [6, 29-31].

Our group set out to discover novel small molecules to target tumors with NF1 deficiency [32]. We developed and conducted a high-throughput synthetic lethality screen to discover small molecules that selectively target yeast lacking the homolog of NF1, IRA2 [32]. We identified multiple lead candidates including the previously described UC-1, an inhibitor of CTK1/CDK9 mediated processes [32]. Targeting this process appears to be effective in models of both NF1 deficient yeast and MPNSTs, as well as in Ras-dysregulated pancreatic ductal adenocarcinoma $[32,33]$. A second screen using the yeast platform also identified another lead candidate, the isoxazoloanthrone Y100, as being synthetic lethal with ira $2 \Delta$ yeast, hereafter referred to as $n f 1 \Delta$. In the present study, we describe the mechanisms by which Y100 inhibits cell growth and/or induces cell death in $n f 1 \Delta$ deficient yeast and NF1-deficient tumor cells.

\section{RESULTS}

\section{Identification of Y100}

We conducted a high-throughput phenotypic screen to identify small molecules that selectively target cells lacking a brewer's yeast homolog of NF1, IRA2. Saccharomyces cerevisiae lacking the Ras suppressor gene IRA2 (nf1 ) were exposed to small molecules selected for structural diversity and drug-like properties (Figure 1A) [32]. The screen was conducted in erg6 6 strains to facilitate access of the test compounds to the yeast. Molecules that targeted $n f 1 \Delta$ cells without affecting $N F 1$ wild-type cells were considered "hits." Using this approach, we previously identified a small molecule that targets a CTK1 mediated process in yeast, resulting in selective inhibition of $n f 1 \Delta$ yeast growth [32]. We subsequently screened an additional $>5,100$ small molecules with this platform. In the present study, we describe efforts to identify the mechanism of action of a hit from this second screen, Y100 (Figure 1B). Y100 (CID 790239) and an analog (Y100B, CID 790235) potently and selectively inhibit growth/viability of $n f 1 \Delta$ yeast with minimal to no impact on $N F 1$ wild-type yeast cells (Figure $1 \mathrm{C}$ and $1 \mathrm{D}$ ). The $\mathrm{IC}_{50}$ in $n f 1 \Delta$ yeast of $\mathrm{Y} 100$ was $4.46 \mu \mathrm{M}$, and the $\mathrm{IC}_{50}$ of $\mathrm{Y} 100 \mathrm{~B}$ in $n f 1 \Delta$ yeast was $14.2 \mu \mathrm{M}$, a difference that is likely due to the structural difference between the two molecules. The sensitivity of $n f 1 \Delta$ yeast to Y100 was not affected by deletion of ERG6 (Figure 1C).

The mechanism by which these molecules target $n f 1 \Delta$ yeast was unknown. To identify potential mechanisms of action or targeted pathways, we performed a high copy suppressor screen. Briefly, this screen involves treating yeast containing a library of high copy plasmids that encode segments of the $S$. cerevisiae genome to identify potential "suppressors" of sensitivity to a small molecule [34, 35]. Cells overexpressing yeast genes were grown on agar containing $10 \mu \mathrm{M}$ Y100B, vehicle (DMSO), or an unrelated small molecule identified in a previous screen (serving as a counter screen to exclude nonspecific suppressors). Colonies that survived on both vehicle and Y100B but not the counter screen molecule were isolated and the plasmids were sequenced to identify which genes were encoded in the plasmid. Highlighted genes with annotated functions are listed in Table 1, with additional genes on suppressor plasmids listed in Supplementary Table 1A [36]. The screen for suppressors of Y100 sensitivity was enriched for plasmids containing genes that encode proteins involved in autophagy or mitochondrial maintenance, among others. Gene Ontology terms were assigned to high copy 
Table 1: Selected high copy suppressor screen hits

\begin{tabular}{ll}
\hline Gene & Function \\
\hline$P C P 1$ & Mitochondrial serine protease, homolog of human $P A R L$, required for mitochondrial maintenance \\
$A T G 23$ & Membrane protein required for macroautophagy, cytosol to vacuole targeting pathway \\
$A T G 38$ & Component of autophagy-specific PIK3CA complex, required for macroautophagy \\
$S S K 1$ & Osmosensor, required for mitophagy \\
PRY1 & Sterol binding, might contribute to detoxification of hydrophobic molecules \\
AIM45 & May be involved in oxidative stress response \\
$I R S 4$ & Localizes Atg17p to pre-autophagosomal site, regulates autophagy \\
NAR1 & Required for Fe-sulfate protein maturation, involved in oxidative stress tolerance \\
$C S R 2$ & Ubiquitin protein ligase binding protein, may regulate endocytosis \\
\hline
\end{tabular}

Potential suppressors of Y100 and their annotated functions.

suppressor screen hits to determine functional enrichment of the genes identified. $14.1 \%$ of the identified suppressors had an autophagy or vacuole-related term assigned, while $15.1 \%$ of the suppressor genes were labeled with a mitochondria-related term (Supplementary Table 1B).

\section{Y100 inhibits growth/viability and modulates proteostasis and mitochondrial health in NF1 deficient human tumor cells}

We next evaluated the effect of Y100 treatment on NF1 deficient U87-MG and U251-MG glioblastoma cells. U87-MG cells exhibit decreased NF1 due to PKC-driven proteasome-mediated degradation of the protein, while U251-MG cells have a frameshift mutation in exon 13 of one allele of $N F 1$, forming a premature stop codon, and deletion of the second allele [15]. The growth/viability of both cell lines was potently inhibited with 3 days of treatment with Y100 (Figure 2A). Additionally, removal and washout of the drug within 30 minutes and subsequent evaluation at 72 hours resulted in a similar reduction in viability as a sustained 72-hour treatment, suggesting that the compound irreversibly binds its target, or that Y100's effect is rapid and has a long duration (Figure 2B).

We evaluated apoptosis and necroptosis as potential mechanisms of Y100 induced cell death. The mechanism

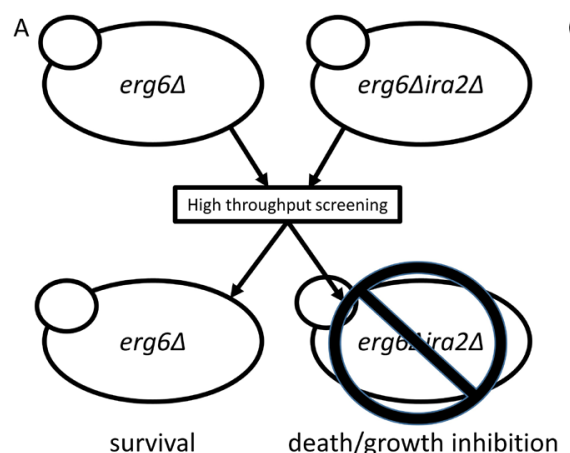

C

B

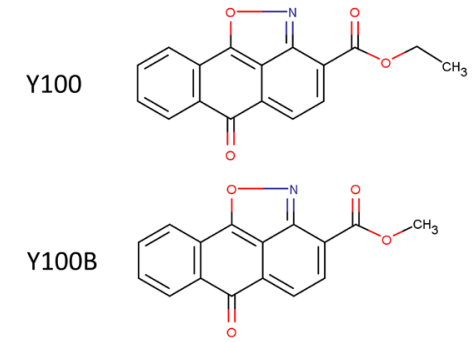

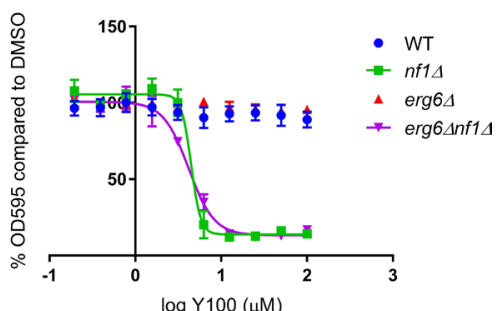

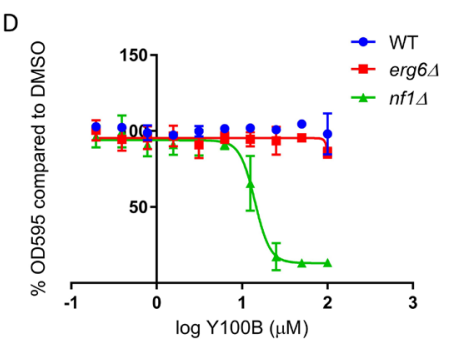

Figure 1: Y100 and Y100B are synthetic lethal with a yeast model of NF1 loss. (A) A schematic of the high throughput screen for small molecules that target a yeast model of NF1 deficiency. erg6 4 and erg6 $4 n f 1 \Delta$ yeast were screened against $~ 5,100$ small molecules. Cell death/growth was determined by measuring $\mathrm{OD}_{600}$. Small molecules that induced slow growth or death of the erg6 $4 \mathrm{nf} 1 \Delta$ yeast without affecting the erg64 yeast strain were considered hits. (B) Structure of Y100 and Y100B. (C-D) Treatment of yeast strains for $18 \mathrm{~h}$ with $0.2-100 \mu \mathrm{M}$ Y 100 or Y100B results in selective inhibition of $n f 1 \Delta$ strains. Control strains are unaffected. Error bars are standard deviation; graph is the average of three (Y100) or two (Y100B) independent experiments. 
of action of Y100 appears to be caspase-independent (Supplementary Figure 1A). Additionally, while the effect of Y100 was abrogated by necrostatin-1 (an inhibitor of the necroptosis effector RIPK1), neither siRNA-mediated knockdown of RIPK1 nor inhibition of RIPK3 with GSK'872 was sufficient to prevent Y100-mediated cell death (Supplementary Figure 1B and 1C). Therefore, while Nec-1 inhibited the effect of Y100, the mechanism of action is likely necroptosis-independent.

The high copy suppressor screen in yeast described above suggested that Y100 might target a process involved in autophagy and/or mitochondrial maintenance. To evaluate the effect of Y100 on autophagy, we treated U87-MG cells with Y100 and evaluated the accumulation of the autophagy protein p62 as a marker of autophagy inhibition. Y100 treatment induced the accumulation of p62, suggesting increased levels of p62-linked protein and inhibition of autophagy. (Figure 2C). Unlike the autophagy inhibitor hydroxychloroquine, however, Y100 treatment does not result in accumulation of lipidated LC3B (LC3B-II), suggesting that it causes p62 accumulation via a distinct mechanism (Figure 2D). These data were recapitulated by immunofluorescent microscopy of p62 and LC3B in Y100 treated U87-MG cells (Figure 2E). Y100 also induced the accumulation of lysine 63 (K63) and lysine 48 (K48) polyubiquitin linked protein in U87MG cells (Figure 2F-2G). K48-linked proteins are thought to be destined for proteasome-mediated degradation, while K63-linked proteins are targeted to autophagosomes [37-40]. These data suggest that Y100 treatment disrupts proteostasis, but it is unclear whether these proteins are destined for autophagic clearance, proteasome-mediated degradation, or both. One possibility is that Y100 is an inhibitor of the proteasome. An MV-151 active site probe assay suggested that Y100 is not a direct inhibitor of the proteasome and therefore is disrupting proteostasis by modulation of autophagy or another mechanism (Supplementary Figure 2).

\section{Y100 disrupts mitochondrial homeostasis and induces the formation of mitochondrial superoxide radicals}

Plasmids from the screen for suppressors of Y100 also contained genes that encode proteins involved in mitochondrial maintenance and stability (Table 1, Supplementary Table 1A and 1B). We assessed the effect of Y100 on the mitochondria of mammalian cells with the mitochondrial marker Tom 20 and the polarization-dependent mitochondrial marker Mitotracker Red (Figure 3A). Cells treated with Y100 had a less defined mitochondrial network (Tom20) and contained puncta of polarized mitochondria (Mitotracker Red "hotspots") when compared to cells treated with a vehicle control. In order to confirm these findings, we examined mitochondrial polarization after Y100 treatment using the mitochondrial polarization-dependent dye JC-1
(Supplementary Figure 3). We observed the formation of polarized mitochondrial "hotspots" (red) within a broader network of depolarized mitochondria (green, Supplementary Figure 3). This "hotspot" phenotype was previously observed upon inhibition of ATP synthase with oligomycin as well as knockdown of the mitochondrial heat shock chaperone protein Tid1 [41]. We evaluated cellular Tid1 content and Mitotracker Red signal in U87-MG cells within a range of 30 minutes to 24 hours of Y100 exposure. We observed a loss of Mitotracker Red signal at shorter time points (30 minutes- 2 hours) followed by the return of Mitotracker Red signal at later time points, suggesting that Y100 induced a rapid but transient depolarization of the mitochondrial network. Furthermore, Tid1 was retained for several hours after Y100 treatment but was reduced at the time points during which we observe Mitotracker Red hotspots (Figure 3B, 8-24 hours).

\section{Treatment with Y100 induces an oxidative stress response}

To better understand the mechanism of action of Y100, we examined the transcriptional response of cells following treatment with Y100 as compared to cells treated with a vehicle control. Y100 treatment resulted in broad transcriptional changes as compared to a vehicle control (Supplementary Table 2). The transcripts with the greatest fold change are displayed in Table 2 . We observed a 2.74 and $1.89 \log$ ratio change, respectively, of HMOX1 and OSGIN1/OKL38, which have both been identified as responsive to oxidative stress as well as regulators of the cellular response to oxidized phospholipids [42, 43]. Y100 treatment led to a $1.32 \log$ ratio increase in PPIF (CypD) transcripts, an effector of the mitochondrial permeability transition that has been linked to Ras transformation [44]. The addition of a CypD inhibitor (cyclosporine A, CsA) did not prevent cell death, suggesting that although there was a significant increase in PPIF transcripts following Y100 treatment, PPIF protein is not required for Y100mediated cell death (Supplementary Figure 1D).

We directly evaluated Y100 treated cells mitochondrial superoxide. Y100 treatment of U87-MG cells for 30 minutes to 24 hours resulted in the presence of superoxide radicals in the mitochondria (Figure 4A). Y100 treatment also induced DNA damage as indicated by the presence of gamma-H2AX (Figure 4B, 4C). Finally, pretreatment with the glutathione synthesis inhibitor buthionine sulfoximine moderately affected the sensitivity of U87-MG cells to Y100 (Figure 4D). Y100 treatment also resulted in a reduction of transcripts related to mitotic processes, such as CCNB1, CENPA, PLK1, AURKA, and $K I F 18 A$ (Table 2). This transcriptional response may be indicative of a DNA-damage-induced cell-cycle arrest. In summary, these data suggest that Y100 induces an oxidative stress and DNA damage response, possibly a result of mitochondrial superoxide formation. 

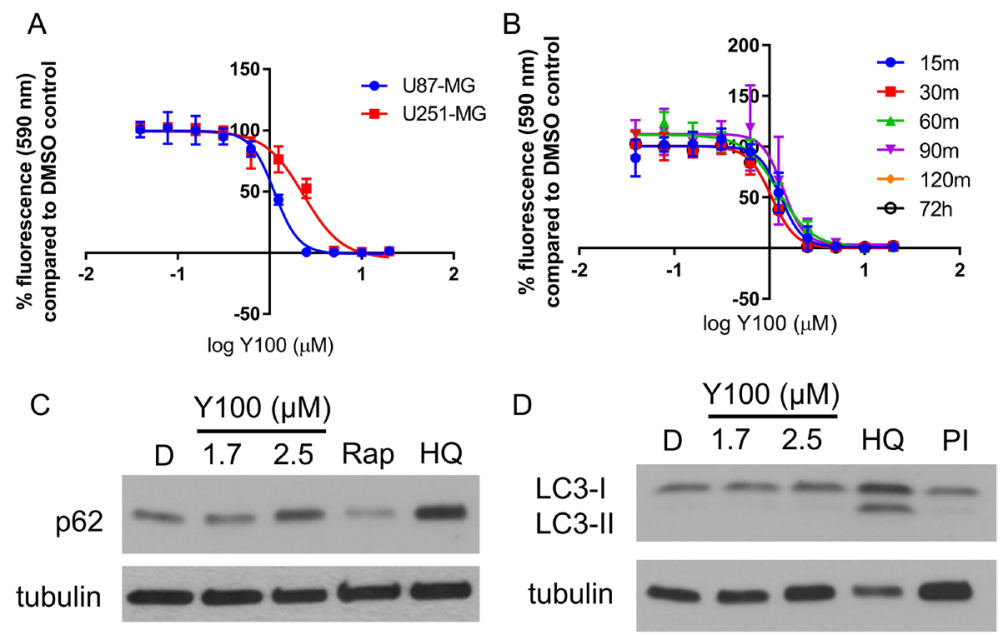

E

DNA

LC3B

p62

Merge
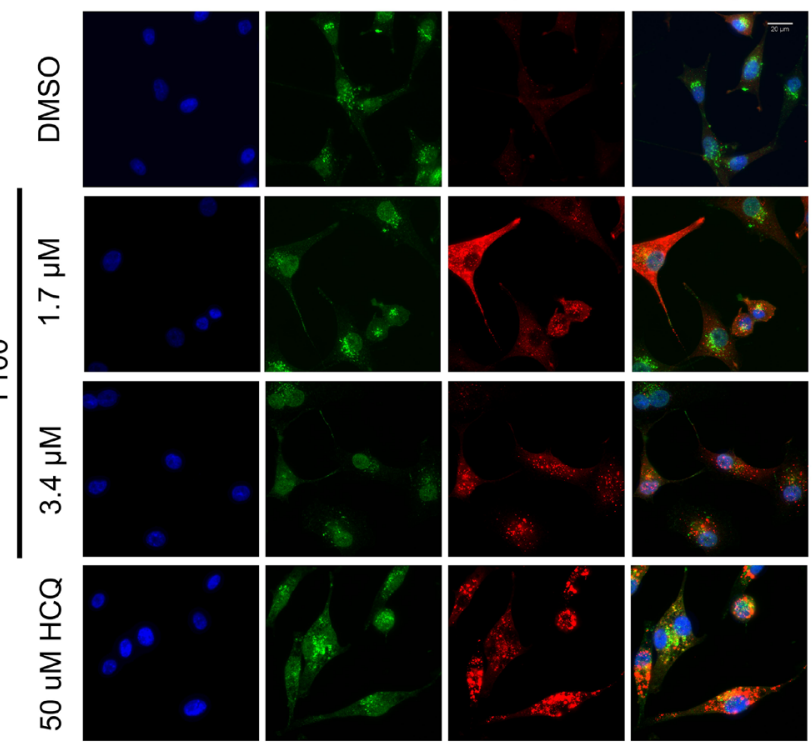

F

D $\frac{\mathrm{Y} 100(\mu \mathrm{M})}{1.73 .410 \mathrm{HQ} P \mathrm{PI}}$

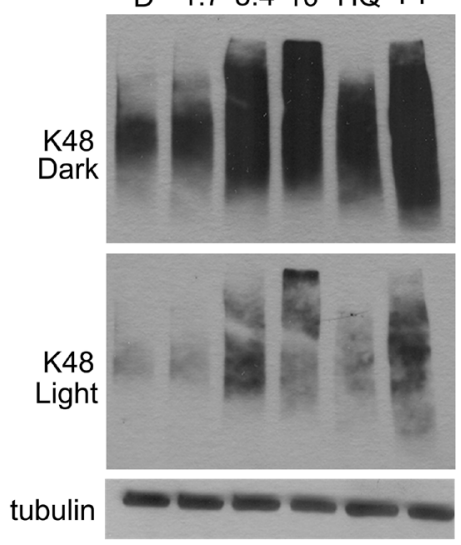

G

D $\frac{\mathrm{Y} 100(\mu \mathrm{M})}{1.73 .410 \mathrm{HQ} \mathrm{PI}}$

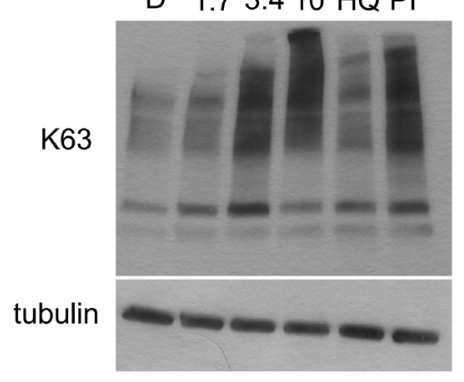

Figure 2: Y100 inhibits NF1 deficient mammalian cells and modulates markers of proteostasis. (A) NF1-deficient U251MG and U87-MG glioblastoma cells were treated with 0.039-20 $\mu$ M Y100 for 72 hours. Error bars represent the standard deviation of four technical replicates. IC $_{50}$ Y100 U87: $1.13 \mu \mathrm{M}, \mathrm{IC}_{50}$ Y100 U251-MG: $2.33 \mu \mathrm{M}$. (B) The effect of Y100 on cell growth/viability appears to be rapid and irreversible. U87-MG cells were treated with 0.039-20 $\mu \mathrm{M}$ Y100 for 30 minutes-72 hours. At timepoints, cells were rinsed with PBS and replaced with drug-free culture media. Data for all timepoints was collected at $72 \mathrm{~h}$. Error bars represent the standard deviation of 
four technical replicates. (C) Y100 treatment induces accumulation of the autophagy marker p62. U87-MG cells were treated for 24 hours with vehicle, Y100, or the autophagy inhibitor HCQ. Cells were also treated with $2 \mathrm{~h}$ of MG132 and bortezomib (BTZ) as a control for proteasome inhibition. (D) Y100 does not result in accumulation of the lipidated form of the autophagy marker LC3 (LC3-II). U87-MG cells were treated for 24 hours with vehicle, Y100, HCQ, or the autophagy inducer/mTOR inhibitor rapamycin. (E) Y100 treatment induces accumulation of p62, but not LC3B. U87-MG cells were treated with vehicle, Y100 or HCQ for 24 hours and immunolabeled for LC3B (green) and p62 (red). DNA was stained with DAPI. (F-G) Y100 treatment causes the accumulation of K48- and K63-polyubiquitin linked protein. U87-MG cells were treated with DMSO (-), 1.7/3.4 $\mu \mathrm{M}$ Y100 or HCQ for 24 hours or for 2 hours with $10 \mu \mathrm{M}$ Y100 or $1 \mu \mathrm{M}$ BTZ/10 $\mu \mathrm{M}$ MG-132. K48/K63 linked proteins and alpha-tubulin (loading control) were detected by western blotting.

Table 2: Transcripts with the greatest change upon Y100 treatment

\begin{tabular}{|c|c|c|}
\hline Transcript & $\log _{2}$ ratio (Y100/DMSO) & Parametric $p$-value \\
\hline$H M O X 1$ & 2.74 & 0.0149326 \\
\hline OSGIN1 & 1.888969 & 0.0012831 \\
\hline OKL38 & 1.643856 & 0.0361717 \\
\hline PPIF & 1.321928 & 0.0030423 \\
\hline$L A M B 3$ & 1.286304 & 0.0012498 \\
\hline$H K D C 1$ & 1.286304 & 0.0468309 \\
\hline$H B E G F$ & 1.251539 & 0.0013294 \\
\hline$S L C 3 A 2$ & 1.152003 & 0.0290661 \\
\hline CCNE2 & 1.120294 & 0.0193412 \\
\hline SLC1A5 & 1.089267 & 0.0122129 \\
\hline DHRS9 & 1.089267 & 0.0492717 \\
\hline$U N K L$ & 1.058894 & 0.0130697 \\
\hline$H S P B 8$ & 1.058894 & 0.0037441 \\
\hline SPHK1 & 1.029146 & 0.0209474 \\
\hline$C L D N 1$ & 1 & 0.0166466 \\
\hline CDK5RAP2 & 1 & 0.0157465 \\
\hline CPA4 & -2.003602237 & 0.0381814 \\
\hline IFIT1 & -1.475084883 & 0.0062619 \\
\hline$C C N B 1$ & -1.384049807 & 0.0085255 \\
\hline PLK1 & -1.304511042 & 0.0065993 \\
\hline C13orf 34 & -1.250961574 & 0.0181284 \\
\hline HCP5 & -1.220329955 & 0.0109714 \\
\hline CENPA & -1.176322773 & 0.0140188 \\
\hline KIF18A & -1.169925001 & 0.006931 \\
\hline AURKA & -1.15704371 & 0.0016516 \\
\hline$H M M R$ & -1.150559677 & 0.0246998 \\
\hline$C C D C 85 A$ & -1.14404637 & 0.0013779 \\
\hline METTL7A & -1.111031312 & 0.0192033 \\
\hline$D L G A P 5$ & -1.111031312 & 0.0076279 \\
\hline$N E K 2$ & -1.084064265 & 0.0000623 \\
\hline$D L G A P 5$ & -1.070389328 & 0.0095592 \\
\hline SYNC1 & -1.070389328 & 0.028098 \\
\hline
\end{tabular}

RNA expression from Y100 treated cells was compared to vehicle treated cells. The transcript identity, $\log _{2}$ change and parametric $p$-value are listed. The ratio of gene expression and parametric $p$-value for Y100 treated cells as compared to a DMSO control is displayed. 

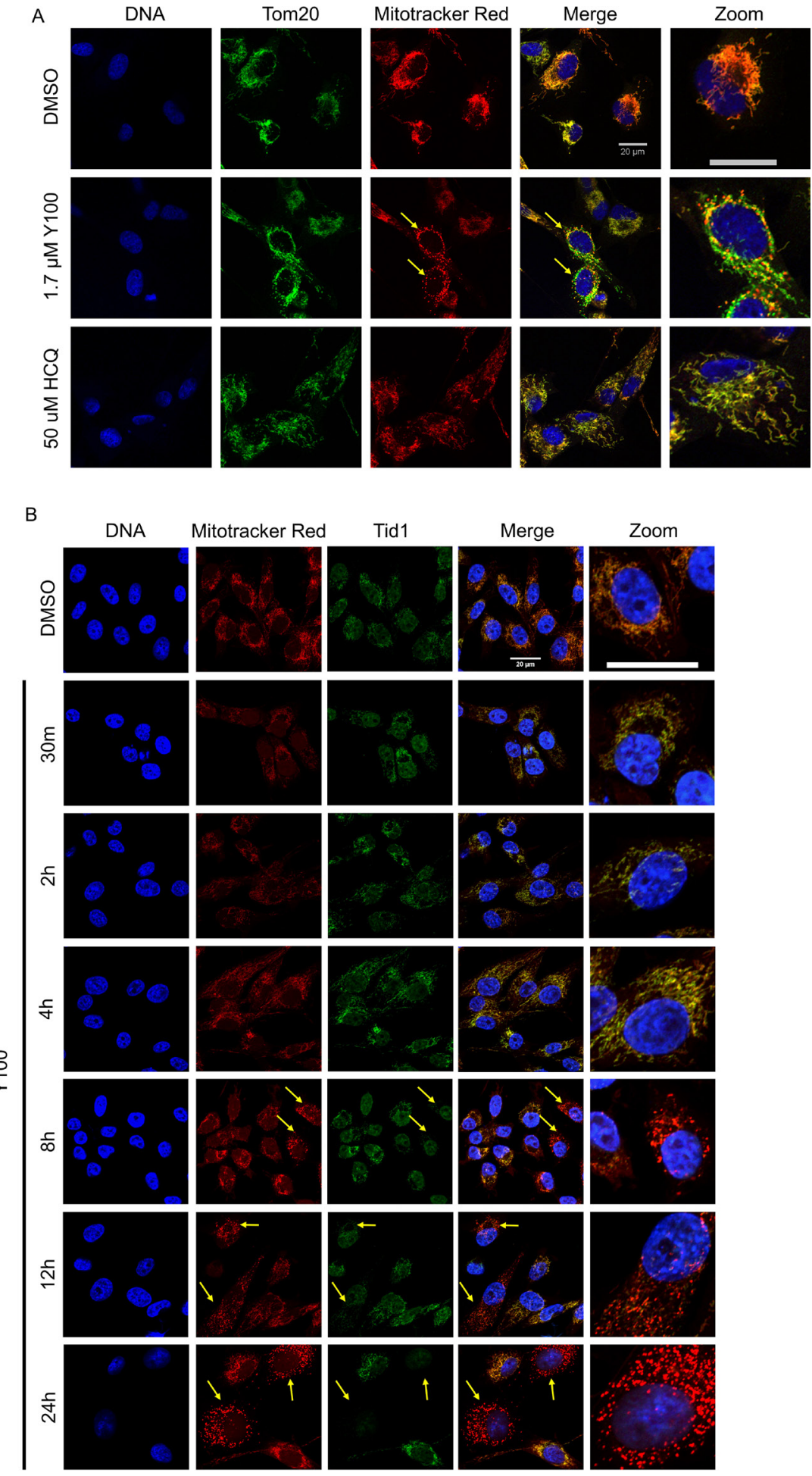

Figure 3: Y100 treatment causes U87-MG cells to develop polarized mitochondrial "hotspots" and cells lacking Tid1. (A) U87-MG cells were treated for 24 hours with vehicle, Y100 or HCQ and immunolabeled for Tom20 (green), a total mitochondrial marker, and Mitotracker (red), a marker of polarized mitochondria, and imaged on a confocal microscope. Treatment of U87-MG cells with Y100 induced the formation of polarized mitochondrial "hotspots" along the mitochondrial network (hotspot positive cells indicated with arrows). These hotspots are not observed with autophagy inhibition. (B) Hotspot-positive cells have reduced, or lack, Tid1, a mitochondrial heat shock chaperone protein. U87-MG cells were treated with vehicle or Y 100 for 30 minutes-24 hours, immunolabeled for mitochondrial heat shock chaperone protein (Tid1, green) and polarized mitochondria (Mitotracker, red), and imaged on a wide-field microscope. Mitochondrial puncta are first observable at 8 hours of Y100 treatment. Cells with polarized mitochondrial puncta contain low to no observable Tid1 signal (indicated with arrows). 


\section{Y100 rapidly induces oxygen consumption and altered mitochondrial bioenergetic capacity}

Due to the changes in mitochondrial phenotype observed after Y100 treatment, we hypothesized that Y100 treatment impacts metabolism in NF1-deficient tumor cells. To evaluate this hypothesis, we performed metabolic profiling of U87-MG cells following treatment with Y100 (Figure 5A, 5B). Three baseline measurements were taken, followed by injection of vehicle, Y100, CCCP (a protonophore that induces mitochondrial depolarization), oligomycin (an ATP synthase inhibitor), antimycin A (a cytochrome $\mathrm{C}$ reductase inhibitor), and bafilomycin $\mathrm{A} 1$ (an autophagy inhibitor). Following this injection, oxygen consumption rate (OCR) and extracellular acidification rate (ECAR) measurements were taken every six minutes for two hours. These measurements are used to evaluate oxidative phosphorylation (OXPHOS) and glycolysis, respectively. Surprisingly, the changes in OXPHOS and glycolysis upon Y100 treatment were not similar to treatment with oligomycin, which inhibited OXPHOS, increased glycolysis, and has been shown to induce the formation of mitochondrial hotspots [41]. Instead, Y100 treatment caused a rapid increase in OXPHOS comparable to treatment with CCCP. We hypothesized that NF1 deficient cells are more dependent on mitochondrial homeostasis than wild-type cells. To test this hypothesis, we treated wild-type and $n f 1 \Delta$ yeast with CCCP. We observed that CCCP is selective for $n f 1 \Delta$ yeast, suggesting that these cells are more dependent on mitochondrial homeostasis than their wild-type counterparts (Figure 5C).

Given that Y100 and CCCP both have differential activity in wild-type and $n f l \Delta$ yeast, and the similar metabolic profile of these molecules on NF1 deficient glioblastoma cells, we postulated that Y100 may be a mitochondrial uncoupler. To assess this, we profiled the
A
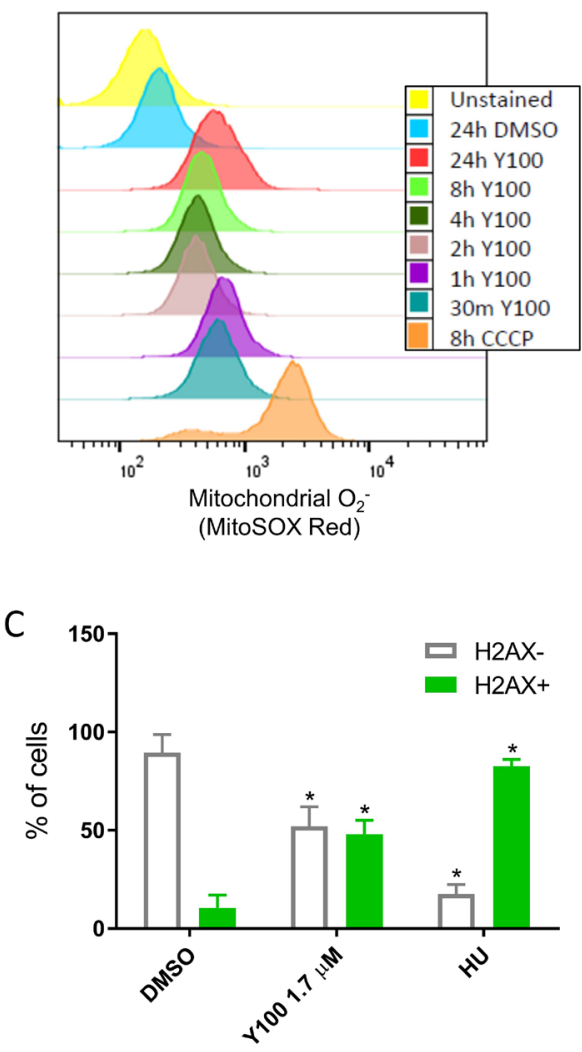

B
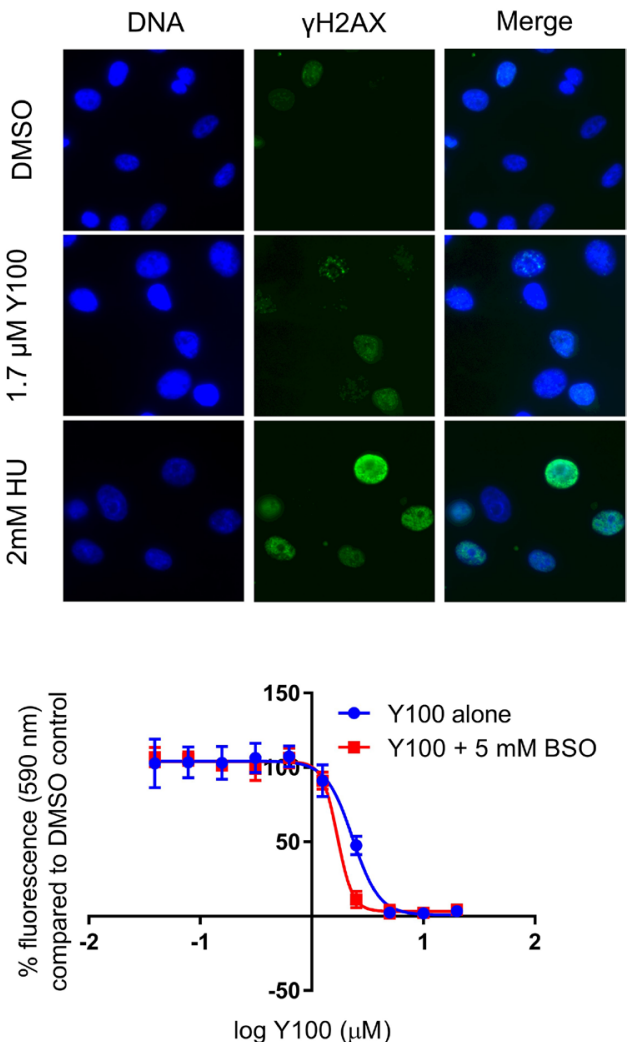

Figure 4: Y100 treatment causes mitochondrial superoxide and DNA damage. ROS scavenging reagents abrogate the effect of Y100. (A) U87-MG cells were treated with vehicle, CCCP, or Y100 for a range of times from 30 minutes to 24 hours. Cells were stained with the mitochondria superoxide specific reagent MitoSOX Red, and analyzed by flow cytometry. Y100 and CCCP treatment induce mitochondrial superoxide. Y100 induced superoxide is detectable within 30 minutes of treatment. (B) Y100 induces DNA damage. U87-MG cells were treated for 24 hours with DMSO, Y100, or the nucleotide synthesis inhibitor hydroxyurea (HU). $\gamma \mathrm{H} 2 \mathrm{AX}$ (green) was immunolabeled as a marker of DNA damage, imaged with a wide-field microscope, and quantified in (C), where 100 cells per condition were scored as H2AX positive (3 or more nuclear foci, or pan-nuclear staining) and H2AX negative (less than three nuclear foci). Values are the average of three experiments. $\left(^{*}\right)$ indicates a significant difference as compared to the DMSO control, $p<0.005$, error bars are standard error of the mean. (D) The GSH synthesis inhibitor buthionine sulfoximine (BSO) slightly potentiates the effect. U87-MG cells were pretreated with vehicle or BSO for 2 hours. Pretreatment media was replaced with media containing media of the same composition with $0.39-2 \mu \mathrm{M}$ Y100 added. Cells were incubated for $72 \mathrm{~h}$ with drug. Viability/growth was measured with alamarBlue fluorescence. 
mitochondrial bioenergetic capacity of Y100 treated cells by performing a modified Mito Stress Test, which utilizes serial injections of oligomycin, FCCP (an uncoupling agent), and a combination of antimycin $\mathrm{A}$ and rotenone (an electron transport chain inhibitor) to characterize cellular bioenergetic potential (Figure 5D). In order to determine the uncoupling capacity of Y100 alone, FCCP was substituted with Y100. Y100 increased OCR after oligomycin addition, but not to the same degree as FCCP. Additionally, oxygen consumption in Y100-treated cells remained elevated upon addition of rotenone and antimycin A. This finding indicates that Y100-induced oxygen consumption may in part be caused by changes to mitochondria-independent oxygen consumption, rather than mitochondrial uncoupling.

\section{DISCUSSION}

\section{Model for Y100's mechanism of action}

In the present study, we demonstrate that Y100 perturbs proteostasis, mitochondrial function, and mitochondrial superoxide in NF1-deficient cancer cells and is synthetic lethal with NF1 loss in a yeast model. It may be that this molecule or others that induce a similar cellular response could be employed in a therapeutic setting to treat malignancies driven by NF1 loss.

Our working model is that Y100 has a multimodal mechanism of action resulting from its induction of mitochondrial superoxide. We observed induction of genes such as HMOX1, OSGIN, and PPIF after 8 hours of Y100 treatment, indicating that Y100 may promote an oxidative stress response and disturb mitochondrial homeostasis. Genes involved in cell division were downregulated upon treatment with Y100, suggesting that Y100-mediated toxicity may be in part due to cell cycle disruption that results from a DNA damage response or other mechanisms. We hypothesize that the superoxide generated by Y100 causes DNA damage, proteotoxicity, and cell death.

The direct molecular target of Y100 has yet to be determined. Y100-induced cell death appears to be caspase-independent, RIPK1/3-independent, and PPIFindependent. Our data suggest that Y100 treatment
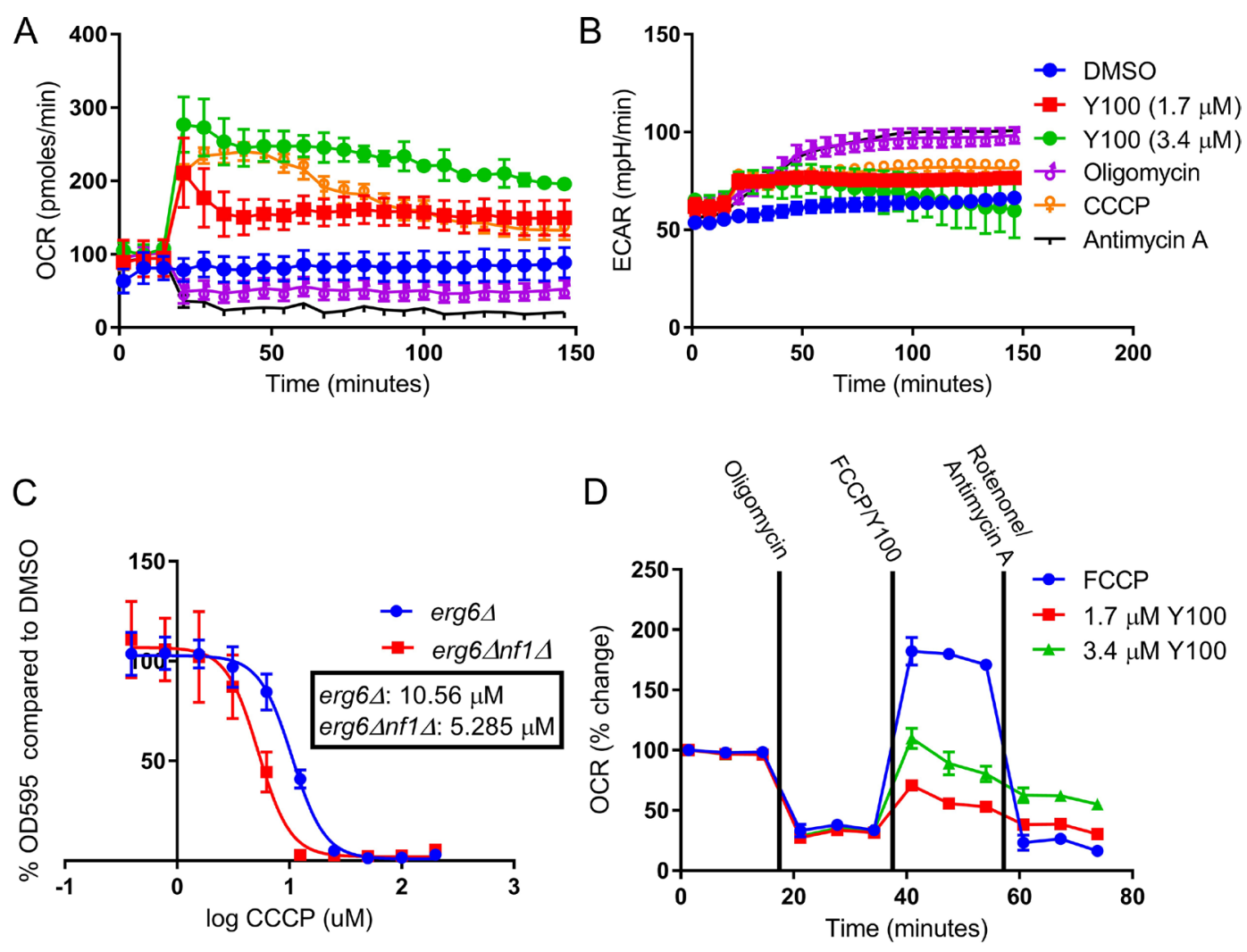

Figure 5: Y100 disrupts mitochondrial homeostasis. (A-B) Y100 rapidly induces increased oxygen consumption, and slightly increases extracellular acidification. Metabolic function (oxygen consumption rate, OCR; extracellular acidification rate, ECAR) was measured at baseline and after injection of mitochondrially targeted agents (oligomycin, CCCP, antimycin A) as well as vehicle and Y100 (injected after 3 baseline measurements). (C) Cells lacking IRA2 have increased sensitivity to the mitochondrial uncoupling agent CCCP. Yeast were treated for 18 hours in the presence of CCCP, and growth/cell death was measured with $\mathrm{OD}_{600}$. (D) Y100 increases oxygen consumption by mechanisms independent of electron transport chain uncoupling. We profiled the mitochondrial bioenergetic capacity of Y100 treated cells by performing a modified Mito Stress Test, which utilizes serial injections of oligomycin, FCCP, and a combination of antimycin A and rotenone to characterize cellular bioenergetic potential. In some samples, FCCP was substituted with Y100. 
results in transient mitochondrial depolarization, dysregulation of mitochondrial homeostasis, and generation of mitochondrial superoxide. It may be that accumulation of p62 as well as K63 polyubiquitin-linked and K48 polyubiquitin-linked proteins is a consequence of oxidative stress, as has previously been observed $[37,45,46]$.

We also observed that mitochondrial uncoupling with CCCP was more toxic to a yeast model of NF1 loss as compared to wild-type yeast. However, Y100 has a much larger therapeutic index in the yeast model than CCCP, suggesting that there could be additional mechanisms by which Y100 targets cells with NF1 loss, such as differences in ROS levels or ROS sensitivity. This mechanism could be clarified in future studies by testing the basal, CCCP, and Y100-induced ROS levels of the NF1 wild-type and deficient yeast model. Furthermore, our data showed that Y100 induced mitochondria-independent oxygen consumption, which could be the result of NADPH oxidase (NOX) pathway activation or other metabolic pathways. NOX activation is a particularly interesting candidate pathway for future studies with Y100 as NOX function has been shown to be critical for Ras-driven transformation.

\section{Metabolic requirements of NF1 deficient cells}

Modulation of metabolism may be a worthwhile strategy for targeting NF1-deficient cells. Our data indicate that Y100 disrupts mitochondrial homeostasis, suggesting this may be one route by which Y100 targets these cells. Prior to this study, other research indicated that NF1 is localized to the mitochondria and regulates metabolism $[47,48]$. More recent work by Masgras, et al. demonstrated that NF1 deficiency causes metabolic dysregulation (reduced respiration and increased glycolysis) that is regulated by mitochondrial ERK-TRAP1-mediated inhibition of succinate dehydrogenase and, furthermore, that NF1 dysregulated tumors require this mechanism for tumor growth [49]. These data suggest that because NF1 signaling and metabolic pathways are intrinsically linked, approaches that alter tumor metabolism may target a key vulnerability of NF1-deficient tumors. For example, NF1deficient tumors are sensitive to the mTORC1/2 inhibitor AZD8055 [50]. In addition, it may be therapeutically beneficial to combine small molecules, such as Y100, that disrupt metabolic processes with other targeted therapies. For example, it was recently shown that the combination of mTOR inhibition and MEK inhibition had a synergistic effect in inhibiting the growth of a genetically engineered model of MPNSTs [51]. Fatty acid synthesis and lipid metabolism represents another potential targetable metabolic pathway in these tumors, as MPNST rely on fatty acid synthesis for tumor growth and cellular survival [52]. Inhibition of glutamine utilization via glutaminase inhibition has also been proposed for treatment of gliomas and NF1-deficient tumor cells [53, 54].

\section{Sensitivity of NF1 deficient cells to oxidative and proteotoxic stress}

Tumor cells with Ras/NF1 dysregulation have been shown to be sensitive to disruption of cellular reactive oxygen species management and proteotoxicity management mechanisms. DeRaedt and colleagues have observed that tumor cells lacking NF1 were sensitive to reactive oxygen species-induced proteotoxic stress [55]. Similarly, Shaw et al. observed that a small molecule inducer of reactive oxygen species, lanperisone, suppressed the growth of KRAS ${ }^{\mathrm{G} 12 \mathrm{D}}$ mutant cells in a murine xenograft tumor model [56]. It remains to be seen whether other factors associated with NF1-deficient tumor formation such as overexpression of $P D F G R A$ or loss of TP53 and PTEN could act as modifiers regarding sensitivity to elevated ROS and disruption of proteostasis $[23,57,58]$. These data, as well as our own, strongly suggest that induction of oxidative and proteotoxic stress may be a tractable therapeutic approach for targeting these tumors with loss of NF1 or Ras gain-of-function mutations.

\section{MATERIALS AND METHODS}

\section{Reagents}

Y100 and Y100B were synthesized by Chembridge Corp (San Diego, CA). The synthesis of Y100 and Y100B was first described by Gornostaev and Lavrikova [59]. Necrostatin-1 (Nec-1) and buthionine sulfoximine (BSO) were purchased from Enzo Life Sciences (Farmingdale, NY), Q-VD-OPh hydrate (QVD) was purchased from ApexBio (Houston, TX), GSK'872 (RIPK3 inhibitor) and oligomycin $(\mathrm{A} / \mathrm{B} / \mathrm{C})$ were purchased from Calbiochem/ EMD Millipore (Billerica, MA), carbonyl cyanide m-chlorophenylhydrazone (CCCP), hydroxyurea (HU), and poly-L-lysine were purchased from SigmaAldrich (St. Louis, MO), antimycin A and cyclosporine A were purchased from Alfa Aesar (Haverhill, MA), and hydroxychloroquine sulfate (HCQ) was purchased from Spectrum Chemicals (New Brunswick, NJ). Stock solutions of all molecules were prepared in 100\% DMSO with the exception of HCQ and HU, which were prepared in phosphate buffered saline without calcium and magnesium (Corning \#21-040-CV).

\section{High copy suppressor screen}

Yeast (MDW320, Table 3) were transformed with $1 \mu \mathrm{g}$ of the $S$. cerevisiae AB320 genomic library in YEp13 (ATCC 37323) or empty vector (YEp13) using a transformation master mix containing $37 \% \mathrm{w} / \mathrm{v}$ polyethylene glycol MW 3350, $110 \mu \mathrm{M}$ lithium acetate, and $307 \mu \mathrm{g} / \mathrm{mL}$ salmon sperm carrier DNA in sterile water. Cells were incubated in the transformation mixture, 
Table 3: Yeast strains used in the present study

\begin{tabular}{ccc}
\hline Strain & Genotype & Source \\
\hline MLY41a & ura3-52 & Lorenz et. al. 1997 [60] \\
MDW057 & As MLY41a erg64 & Wood et. al. [34] \\
MDW028 & As MLY41a ira24 & Wood et. al. [34] \\
MDW035 & As MLY41a erg64ira24 & Wood et. al. [34] \\
MDW320 & ira24 leu2-3 his3-11 & This study \\
\hline
\end{tabular}

including DNA, for 30 minutes at $30^{\circ} \mathrm{C}$ before heat shock for 15 minutes at $42^{\circ} \mathrm{C}$. The cells were washed once with water and then plated on freshly made SC-Leu dropout agar plates with $10 \mu \mathrm{M}$ Y100B, DMSO, or an unrelated tool compound. Individual colonies that grew on Y100B and DMSO but not the unrelated compound plates were then grown on SC-Leu. Plasmid DNA from the surviving yeast was prepared with 25:24:1 phenol:chloroform:isoamyl alcohol and then electroporated into E. coli. Plasmid DNA was isolated from $E$. coli using a QiaPrep Spin MiniPrep kit (Qiagen). Plasmids were restriction digested with the restriction enzyme NdeI at $37^{\circ} \mathrm{C}$ for 1 hour. Cut plasmid DNA was separated on $0.8 \%$ agarose gels to identify unique plasmids. Unique targets were sequenced by the Sanger method using the following primers that recognize sequences on YEp13:

Forward: AAG CGC TCA TGA GCC CGA AGT G Reverse: TCT ATG CGC ACC CGT TCT CG

Sequences were compared known yeast genes to identify high copy sequences using the Saccharomyces Genome Database WU-BLAST2 tool [60]. Functional annotation of high copy suppressor hits with Gene Ontology terms was performed with the Saccharomyces Genome Database YeastMine tool [61].

\section{Cell culture}

U87-MG cells were purchased from ATCC (Manassas, VA). U251-MG cells were purchased from Sigma-Aldrich. U87-MG and U251-MG were passaged regularly and cultured with DMEM (Corning Life Sciences, Corning, NY) in the presence of $10 \% \mathrm{v} / \mathrm{v}$ fetal bovine serum (Atlanta Biologicals; Life Technologies). Immortalized mammary epithelial cells (IMECs) were a kind gift from Dr. James DiRenzo. IMECs were cultured in DMEM/F12 50/50 media supplemented with 5\% FBS, 2 $\mathrm{mM}$ glutamine (Gibco), $5 \mu \mathrm{g} / \mathrm{mL}$ insulin (Akron Biotech), $500 \mu \mathrm{g} / \mathrm{mL}$ hydrocortisone (MP Biomedical), and $10 \mathrm{ng} / \mathrm{mL}$ recombinant human epidermal growth factor (Promega). Cells were routinely verified as mycoplasma free with the MycoProbe kit (R\&D Systems).

\section{Immunofluorescence}

50,000 U87-MG cells were cultured on polyD-lysine coated coverslips (Neuvitro Corporation) or
poly-L-lysine (Sigma) coated coverslips and treated with Y100 (Chembridge) for 24 hours. When labeling polarized mitochondria, cells were treated with 100 nM Mitotracker Red CMXRos in culture media for 30 minutes prior to fixation (Life Technologies). After treatment and labeling, cells were rinsed with PBS. Cells were fixed in methanol-free $4 \%$ paraformaldehyde, $\mathrm{pH}$ 6.9 (Electron Microscopy Services) prepared in PBS (Corning) for 10 minutes at room temperature (RT) and blocked with immunofluorescence buffer $(2 \%$ [v/v] goat serum, $0.2 \%[\mathrm{v} / \mathrm{v}$ ] Triton X-100 and $0.05 \%[\mathrm{w} / \mathrm{v}]$ sodium azide in PBS) at RT. Primary antibody conditions were diluted in IF buffer and used as follows: anti-Tom 20 FL-145 (Santa Cruz, 1:200, RT, 1 hour), anti-Tid1 Ab-2 RS13 (Neomarkers, 1:200 $4^{\circ} \mathrm{C}$, overnight), anti-p-H2AX Ser139-488 N1-431 (BD, 1:100, $4^{\circ} \mathrm{C}, 30$ minutes, no secondary). After primary antibody staining, cells were rinsed 3 times for 5 minutes with PBST. Secondary labeling was performed with 1:600 goat anti-rabbit 488 or 1:800 goat anti-mouse F(ab')2 DyLight 594 or 647 at room temperature for 1 hour (Jackson Immunoresearch) diluted in IF buffer. Cells were then rinsed 2 times for five minutes with PBST and nuclei were labeled with $0.33 \mu \mathrm{g} /$ mL DAPI in PBS for 5 minutes. Coverslips were mounted on glass slides with ProLong Gold (Life Technologies) and imaged. For JC-1 mitochondrial staining, PLL coated coverslips were seeded with 50,000 U87-MG cells and allowed to adhere overnight. The following day cells were treated with $10 \mu \mathrm{M}$ CCCP, $1.7 \mu \mathrm{M}$ Y100, or equivalent volume DMSO in DMEM with $10 \%$ FBS for $12 \mathrm{~h}$. Thirty minutes before the endpoint, the medium was replaced with $1 \mu \mathrm{g} / \mathrm{mL}$ JC- 1 dye in DMEM with $10 \%$ FBS. Live cells were then mounted in 1:1 PBS:ProLong Gold and imaged immediately. Wide-field images were acquired with a Zeiss Imager Z1 wide-field microscope equipped with a $40 \times 1.3$ NA EC Plan-NEOFLUAR objective and Zeiss Axiovision software. Confocal images were acquired with a Nikon A1RSi confocal microscope equipped with a 60X 1.4 NA objective, a DU4 detector unit, and Nikon Elements software. Image processing was performed with Fiji, built on ImageJ2 [62, 63].

\section{Microarray}

$5 \times 10^{5}$ immortalized mammary epithelial cells (IMECs) were cultured overnight and treated with DMSO 
or $1 \mu \mathrm{M}$ Y 100 for 8 hours. Cells were trypsinized, rinsed in PBS and centrifuged. The supernatant was removed and the pellet was frozen at $-80^{\circ} \mathrm{C}$. The RNA was extracted using a Norgen Biotek RNA/DNA/Protein Purification Plus Kit, following the standard operating protocol. $300 \mathrm{ng}$ RNA/sample was labeled using the TargetAmp Nano kit (Epicentre Bio, Madison, WI). RNA was hybridized to an HT12v4 microarray (Illumina, San Diego, CA) overnight in an Illumina hybridization oven. Arrays were scanned with the iScan microarray scanner (Illumina). Analyses were performed using BRB-Array Tools Version 4.2.1. BRB-ArrayTools is an integrated software package for the analysis of DNA microarray data [64]. Variance-stabilizing transformation was applied to raw intensity data, which was then normalized using robust spline normalization and filtered to remove nondetected spots as determined by Illumina BeadStudio Software. Three technical replicates were performed for both conditions. One DMSO replicate was determined to be an outlier and thus eliminated. Differentially expressed genes were identified using a random-variance $t$-test with a $p$-value cutoff of 0.05 [64]. Multiple testing correction was performed using the method of Benjamini and Hochberg. Hierarchical clustering was employed to generate heat maps for subsets of significant genes using the open source software Cluster/Treeview written by Michael Eisen [65]. Cluster and TreeView are programs that provide a computational and graphical environment for analyzing data from DNA microarray experiments or other genomic datasets. Data were uploaded to the Gene Expression Omnibus (accession number GSE86421).

\section{Dose response assays}

To perform drug sensitivity assays in mammalian models, cells were plated to 96-well plates at a concentration of 5,000 cells/well. After overnight incubation, the medium was removed and replaced with $100 \mu \mathrm{L}$ of medium containing 0-20 $\mu \mathrm{M}$ Y100 and DMSO (to normalize DMSO concentrations). In the case of the Nec-1, GSK'872, cyclosporine A, and QVD co-treatment assays, cells were preincubated with these compounds or a vehicle control for $2 \mathrm{~h}$ before being replaced with Y100 +/Nec-1, GSK'872, QVD, cyclosporine A, or vehicle. In the case of the BSO co-treatment assay, cells were incubated with $\mathrm{BSO}$ or media for $48 \mathrm{~h}$ before being replaced with Y100 +/- BSO. Cells were incubated for the noted time with a final 3-hour incubation in 5\% AlamarBlue (Thermo Scientific). The plate was scanned using a Spectramax M2 (Molecular Devices) plate reader at an Ex/Em of 544/590 $\mathrm{nm}$, and fluorescence was normalized to vehicle control wells. Each experiment was repeated 2-3 times with 4 technical replicates per experiment. A representative experiment is shown in each case.

To perform drug sensitivity assays in yeast models (Table 3), log-phase cells were diluted to $0.05 \mathrm{OD}_{600}$.
Drugs were diluted in SC-Complete media starting at $200 \mu \mathrm{M}$, followed by 92 -fold serial dilutions to generate a 10 -point range of concentrations. $75 \mu \mathrm{L}$ of cells were mixed with $75 \mu \mathrm{L}$ of drug dilutions in a 96-well plate, with four technical replicates per concentration. Yeast were incubated for 18 hours at $30^{\circ} \mathrm{C}$. At 18 hours, the $\mathrm{OD}_{600}$ was read using a THERMOmax (Molecular Devices) plate reader and SOFTmax Pro 4.3 LS software. Each experiment was repeated 2-3 times with three technical replicates per experiment. $\mathrm{OD}_{600}$ was normalized to vehicle control wells.

Dose-response curves and $\mathrm{IC}_{50} \mathrm{~s}$ were calculated with the Prism 6 software package (GraphPad, San Diego, CA, USA) by performing a 4-parameter logistic regression with outlier exclusion analysis.

\section{Flow cytometry}

To determine mitochondrial superoxide levels, 500,000 U87-MG cells/well were plated in a 6-well plate and allowed to adhere overnight. The medium was then replaced with cell culture media, and DMSO, $1.7 \mu \mathrm{M}$ Y100, or $10 \mu \mathrm{M}$ CCCP was added to the media at the noted time points. Cells were treated for 30 minutes to 24 hours. 30 minutes before the end of the incubation, MitoSOX Red (Cell Signaling) was added to a final concentration of $1 \mu \mathrm{M}$. At the end of the incubation, cells were rinsed twice with PBS and trypsinized and resuspended in PBS for analysis. The cells were transferred to flow cytometry tubes and analyzed using a MacsQuant VYB 8-color flow cytometer. MitoSOX Red fluorescence was detected using the Y2-A (TdTomato) channel. 30,000 events per sample were collected and cellular debris was gated out of the dataset. This experiment was repeated three times, and a representative experiment is shown. Histograms were generated using the FlowJo or FlowLogic flow cytometry analysis software packages.

\section{MV-151 active site probe assay}

U87-MG cells were plated (500,000 cells per well in a 6-well tissue culture plate) and allowed to adhere overnight. Cells were treated for 24 hours with vehicle control (DMSO), Y100, or a $2 \mathrm{~h}$ incubation of a cocktail of $1 \mu \mathrm{M}$ bortezomib and $10 \mu \mathrm{M}$ MG-132 (proteasome inhibitors) as a positive control. The cells were lysed with digitonin buffer $(250 \mathrm{mM}$ sucrose, $50 \mathrm{mM}$ Tris$\mathrm{HCl} \mathrm{pH} \mathrm{7.5,} 5 \mathrm{mM} \mathrm{MgCl}_{2}, 1 \mathrm{mM}$ dithiothreitol, $2 \mathrm{mM}$ adenine triphosphate, $0.2 \% \mathrm{v} / \mathrm{v}$ nonidet $\mathrm{P} 40,0.025 \%$ $\mathrm{w} / \mathrm{v}$ digitonin). Lysates were incubated with MV-151, a fluorescent probe that binds active proteasome subunits, for 30 minutes at $37^{\circ} \mathrm{C}$ and samples $(10 \mu \mathrm{g}$ total protein per sample) were separated on an SDS-PAGE gel [66, 67]. The gel was then scanned on a Typhoon scanner to detect MV-151 fluorescence, and protein was transferred to a nitrocellulose membrane and probed for alpha-tubulin as a loading control. The experiment was repeated three times. 


\section{RNA interference}

U87-MG cells were plated in a 96-well plate at a concentration of 5,000 cells/well and a 6-well plate at a concentration of $1.48 \times 10^{5}$ cells/well. Cells were transfected with siRNA targeting RIPK1 (Sigma, SASI Hs01_00071803), or a non-targeting control (Sigma, Universal Control \#1) prepared in Lipofectamine 2000 (Invitrogen) and serum-free DMEM (Corning). 96-well plates were transfected with 5 pmol siRNA/well. 6-well plates were transfected with an equivalent amount of siRNA scaled for total volume. After a 48-hour transfection period, cells were treated with Y100 for 48 hours. Dose response assay was performed as described above. Protein samples were acquired 48 and 96 hours post-transfection to verify RIP1 knockdown (Supplementary Figure 2).

\section{Western blotting}

U87-MG cells were plated at a concentration of 500,000 cells per well in a 6-well plate and allowed to adhere overnight. Cells were treated with the noted concentrations and times of controls or Y100. After treatment, cells were harvested with trypsin, rinsed, and lysed with $75 \mu \mathrm{L}$ modified RIPA buffer ( $150 \mathrm{mM} \mathrm{NaCl}, 1 \% \mathrm{v} / \mathrm{v}$ nonidet P $40,0.5 \% \mathrm{w} / \mathrm{v}$ sodium deoxycholate, $0.05 \% \mathrm{w} / \mathrm{v}$ sodium dodecyl sulfate, $50 \mathrm{mM}$ Tris $\mathrm{pH}$ 8.0) containing $1 \mathrm{mM} \mathrm{NaVO}, 1 \mathrm{mM} \mathrm{NaF}$, $1 \mathrm{mM}$ phenylmethylsulfonyl fluoride, $0.1 \mu \mathrm{g} / \mathrm{mL}$ leupeptin, $100 \mu \mathrm{M}$ benzamidine $\mathrm{HCl}, 1 \mu \mathrm{M}$ aprotinin, $0.1 \mu \mathrm{g} / \mathrm{mL}$ soybean trypsin inhibitor, $0.1 \mu \mathrm{g} / \mathrm{mL}$ pepstatin, and $0.1 \mu \mathrm{g} /$ $\mathrm{mL}$ antipain. Protein was quantified with a bicinchoninic acid assay kit (Pierce). $30 \mu \mathrm{g}$ of protein was prepared in $1 \mathrm{X}$ Laemmli sample buffer (50 mM Tris $\mathrm{pH} 6.8,0.02 \% \mathrm{w} / \mathrm{v}$ bromophenol blue, $2 \% \mathrm{w} / \mathrm{v}$ sodium dodecyl sulfate, $10 \% \mathrm{v} / \mathrm{v}$ glycerol, $1 \% \mathrm{v} / \mathrm{v}$ beta-mercaptoethanol, $12.5 \mathrm{mM}$ EDTA) and separated by sodium dodecyl sulfate-polyacrylamide gel electrophoresis on a 4-15\% polyacrylamide gradient gel (Bio-Rad). Protein was transferred to a nitrocellulose membrane, blocked with 5\% nonfat dry milk in TBST and probed with anti-LC3BI/II \#2775 (Cell Signaling, 1:1000, overnight), anti-p62/SQSTM-1 D-3 (Santa Cruz, 1:1000, $1 \mathrm{~h}$ ), anti-alpha-tubulin B-1-2-5 (Santa Cruz, 1:10000, $1 \mathrm{~h}$ ), anti-K63 polyubiquitin \#5921 (Cell Signaling, 1:1000, 1 h), anti-pK48 polyubiquitin \#8081 (Cell Signaling, 1:2000, 1 h), anti-GAPDH ab9485-100 (Abcam, 1:1000, overnight), antiRIP (BD Transduction Laboratories, 1:1000, overnight) in $2 \%$ milk in TBST. Secondary labeling was performed with a one-hour incubation in 1:20000 anti-rabbit HRP or 1:10000 anti-mouse HRP (Jackson Immunoresearch) diluted in 2\% milk in TBST. The film was then exposed to ECL-coated blots (Pierce) and developed using a standard film processor.

\section{Bioenergetic characterization of Y100}

Bioenergetics analysis was performed with a Seahorse XF96 Bioanalyzer (Agilent Technologies, Santa Clara, CA).
Briefly, $2.0 \times 10^{5}$ U87-MG cells were plated in DMEM with $10 \%$ fetal bovine serum, in a Seahorse XF96 Microplate and allowed to adhere overnight. A FluxPack sensor cartridge was equilibrated in XF Calibrant at $37^{\circ} \mathrm{C}$ overnight. Before performing the assay, cells were washed twice in standard XF Base Medium supplemented with pyruvate, glutamine, and glucose. Cells were then incubated in $180 \mu \mathrm{L} \mathrm{XF} \mathrm{media}$ for 45 minutes at $37^{\circ} \mathrm{C}$ with atmospheric $\mathrm{CO}_{2}$. To perform single injection assays, $20 \mu \mathrm{L}$ of $10 \mathrm{X}$ assay molecule in $\mathrm{XF}$ media was prepared and loaded into port A. The assay was run with 3 baseline measurements, followed by injection and 2 hours of data collection to determine changes in oxygen consumption rate (OCR) and extracellular acidification rate (ECAR). To perform the Mito Stress Test, the assay was run as described in the Mito Stress Test kit protocol with $1 \mu \mathrm{M}$ oligomycin, $0.5 \mu \mathrm{M}$ FCCP, and $0.5 \mu \mathrm{M}$ rotenone/antimycin A. For curves containing Y100, FCCP was substituted with Y100. Both experiments were repeated a minimum of three times, with a representative experiment shown. The analysis was performed with Seahorse Wave 2.2/2.3.

\section{ACKNOWLEDGMENTS}

The authors would like to thank Dr. Michael Cole, Dr. Dale Mierke, Dr. Jack Hoopes, Dr. Robert Cramer, and Dr. Jean Francois Trempe for helpful discussions, Dr. Alexei Kisselev for assistance with the MV151 assay, and the DartLab Flow Cytometry core for flow cytometry and Seahorse experimental assistance. The authors would additionally like to thank the Dartmouth Genomics Shared Resource for assistance with microarray experiments.

\section{CONFLICTS OF INTEREST}

The authors have no conflicts of interest to disclose.

\section{GRANT SUPPORT}

This work was funded by NINDS R21 NS060940 to YS, NINDS R01 NS095411-01A1 to YS and NR, a Nancy P. Shea Trust grant to YS, a Prouty Pilot Grant from the Friends of the Norris Cotton Cancer Center to YS, NCI Cancer Center Support Grant CA23108 to the DartmouthHitchcock Norris Cotton Cancer Center, and Children's Tumor Foundation Young Investigator Awards 2014-0112 to RJA and 2016-01-016 to SJB. Funds to purchase the Nikon A1RSi Confocal Workstation were provided by NSF \#DBI-1039423. RJA is an Albert J. Ryan Fellow.

\section{REFERENCES}

1. Ballester R, Marchuk D, Boguski M, Saulino A, Letcher R, Wigler M, Collins F. The NF1 Locus Encodes a Protein Functionally Related to Mammalian GAP and Yeast IRA Proteins. Cell. 1990; 63:851-659. 
2. Dunn GP, Rinne ML, Wykosky J, Genovese G, Quayle SN, Dunn IF, Agarwalla PK, Chheda MG, Campos B, Wang A, Brennan C, Ligon KL, Furnari F, et al. Emerging insights into the molecular and cellular basis of glioblastoma. Genes Dev. 2012; 26:756-84.

3. Dasgupta B, Gutmann DH. Neurofibromin regulates neural stem cell proliferation, survival, and astroglial differentiation in vitro and in vivo. J Neurosci. 2005; 25:5584-94.

4. Lee JS, Padmanabhan A, Shin J, Zhu S, Guo F, Kanki JP, Epstein JA, Look AT. Oligodendrocyte progenitor cell numbers and migration are regulated by the zebrafish orthologs of the NF1 tumor suppressor gene. Hum Mol Genet. 2010; 19:4643-53.

5. Friedman JM. Neurofibromatosis 1. GeneReviews $\left({ }^{\circledR}\right) .1993$.

6. Ratner N, Miller SJ. A RASopathy gene commonly mutated in cancer: the neurofibromatosis type 1 tumour suppressor. Nat Rev Cancer. 2015; 15:290-301.

7. Serra E, Puig S, Otero D, Gaona A, Kruyer H, Ars E, Estivill X, Lázaro C. Confirmation of a double-hit model for the NF1 gene in benign neurofibromas. Am J Hum Genet. 1997; 61:512-9.

8. Redig AJ, Capelletti M, Dahlberg SE, Sholl LM, Mach S, Fontes C, Shi Y, Chalasani P, Jänne PA. Clinical and Molecular Characteristics of NF1-Mutant Lung Cancer. Clin Cancer Res. 2016; 22:3148-56.

9. Sangha N, Wu R, Kuick R, Powers S, Mu D, Fiander D, Yuen K, Katabuchi H, Tashiro H, Fearon ER, Cho KR. Neurofibromin 1 (NF1) defects are common in human ovarian serous carcinomas and co-occur with TP53 mutations. Neoplasia. 2008; 10:1362-72, following 1372.

10. Bell D, Berchuck A, Birrer M, Chien J, Cramer DW, Dao F, Dhir R, DiSaia P, Gabra H, Glenn P, Godwin AK, Gross J, Hartmann L, et al. Integrated genomic analyses of ovarian carcinoma. Nature. 2011; 474:609-15.

11. Verhaak RGW, Hoadley KA, Purdom E, Wang V, Qi Y, Wilkerson MD, Miller CR, Ding LL, Golub T, Mesirov JP, Alexe G, Lawrence M, O'Kelly M, et al. Integrated Genomic Analysis Identifies Clinically Relevant Subtypes of Glioblastoma Characterized by Abnormalities in PDGFRA, IDH1, EGFR, and NF1. Cancer Cell. 2010; 17:98-110.

12. Brennan CW, Verhaak RG, McKenna A, Campos B, Noushmehr H, Salama SR, Zheng S, Chakravarty D, Sanborn JZ, Berman SH, Beroukhim R, Bernard B, Wu CJ, et al. The somatic genomic landscape of glioblastoma. Cell. 2013; 155:462-77.

13. McLendon R, Friedman A, Bigner D, Van Meir EG, Brat DJ, Mastrogianakis GM, Olson JJ, Mikkelsen T, Lehman N, Aldape K, Alfred Yung WK, Bogler O, VandenBerg $\mathrm{S}$, et al. Comprehensive genomic characterization defines human glioblastoma genes and core pathways. Nature. 2008; 455:1061-8.

14. McGillicuddy LT, Fromm JA, Hollstein PE, Kubek S, Beroukhim R, De Raedt T, Johnson BW, Williams SM,
Nghiemphu P, Liau LM, Cloughesy TF, Mischel PS, Parret A, et al. Proteasomal and Genetic Inactivation of the NF1 Tumor Suppressor in Gliomagenesis. Cancer Cell. 2009; 16:44-54.

15. Cichowski K, Santiago S, Jardim M, Johnson BW, Jacks T. Dynamic regulation of the Ras pathway via proteolysis of the NF1 tumor suppressor. Genes Dev. 2003; 17:449-54.

16. Sedani A, Cooper DN, Upadhyaya $M$. An emerging role for microRNAs in NF1 tumorigenesis. Hum Genomics. 2012; 6:23.

17. Subramanian S, Thayanithy V, West RB, Lee CH, Beck AH, Zhu S, Downs-Kelly E, Montgomery K, Goldblum JR, Hogendoorn PCW, Corless CL, Oliveira AM, Dry SM, et al. Genome-wide transcriptome analyses reveal p53 inactivation mediated loss of miR-34a expression in malignant peripheral nerve sheath tumours. J Pathol. 2010; 220:58-70.

18. Stark MS, Bonazzi VF, Boyle GM, Palmer JM, Symmons J, Lanagan CM, Schmidt CW, Herington AC, Ballotti R, Pollock PM, Hayward NK. miR-514a regulates the tumour suppressor NF1 and modulates BRAFi sensitivity in melanoma. Oncotarget. 2015; 6:17753-63. https://doi. org/10.18632/oncotarget.3924.

19. Patel AJ, Liao CP, Chen Z, Liu C, Wang Y, Le LQ, Albers AC, Gutmann DH, Albritton K, Rankin C, Coffin C, Ratner N, Budd G, et al. BET bromodomain inhibition triggers apoptosis of NF1-associated malignant peripheral nerve sheath tumors through Bim induction. Cell Rep. 2014; 6:81-92.

20. Jessen WJ, Miller SJ, Jousma E, Wu J, Rizvi TA, Brundage ME, Eaves D, Widemann B, Kim MO, Dombi E, Sabo J, Hardiman Dudley A, Niwa-Kawakita M, et al. MEK inhibition exhibits efficacy in human and mouse neurofibromatosis tumors. J Clin Invest. 2013; 123:340-7.

21. Jousma E, Rizvi TA, Wu J, Janhofer D, Dombi E, Dunn RS, Kim MO, Masters AR, Jones DR, Cripe TP, Ratner N. Preclinical assessments of the MEK inhibitor PD-0325901 in a mouse model of Neurofibromatosis type 1. Pediatr Blood Cancer. 2015; 62:1709-16.

22. See WL, Tan IL, Mukherjee J, Nicolaides T, Pieper RO. Sensitivity of glioblastomas to clinically available MEK inhibitors is defined by neurofibromin 1 deficiency. Cancer Res. 2012; 72:3350-9.

23. $\mathrm{Ki} \mathrm{DH}, \mathrm{He} \mathrm{S}$, Rodig S, Look AT. Overexpression of PDGFRA cooperates with loss of NF1 and p53 to accelerate the molecular pathogenesis of malignant peripheral nerve sheath tumors. Oncogene. 2017; 36:1058-1068.

24. He S, Mansour MR, Zimmerman MW, Ki DH, Layden HM, Akahane K, Gjini E, de Groh ED, Perez-Atayde AR, Zhu S, Epstein JA, Look AT. Synergy between loss of NF1 and overexpression of MYCN in neuroblastoma is mediated by the GAP-related domain. Elife. 2016; 5.

25. Kaul A, Toonen JA, Cimino PJ, Gianino SM, Gutmann DH. Akt- or MEK-mediated mTOR inhibition suppresses Nf1 optic glioma growth. Neuro Oncol. 2015; 17:843-53.

26. Johannessen CM, Reczek EE, James MF, Brems H, Legius E, Cichowski K. The NF1 tumor suppressor 
critically regulates TSC 2 and mTOR. Proc Natl Acad Sci U S A. 2005; 102:8573-8.

27. Johansson G, Mahller YY, Collins MH, Kim MO, Nobukuni T, Perentesis J, Cripe TP, Lane HA, Kozma SC, Thomas $\mathrm{G}$, Ratner N. Effective in vivo targeting of the mammalian target of rapamycin pathway in malignant peripheral nerve sheath tumors. Mol Cancer Ther. 2008; 7:1237-45.

28. Lim SM, Park HS, Kim S, Kim S, Ali SM, Greenbowe JR, Yang IS, Kwon NJ, Lee JL, Ryu MH, Ahn JH, Lee J, Lee $\mathrm{MG}$, et al. Next-generation sequencing reveals somatic mutations that confer exceptional response to everolimus. Oncotarget. 2016; 7:10547-56. https://doi.org/10.18632/ oncotarget.7234.

29. Weiss B, Widemann BC, Wolters P, Dombi E, Vinks A, Cantor A, Perentesis J, Schorry E, Ullrich N, Gutmann DH, Tonsgard J, Viskochil D, Korf B, et al. Sirolimus for progressive neurofibromatosis type 1-associated plexiform neurofibromas: a neurofibromatosis Clinical Trials Consortium phase II study. Neuro Oncol. 2015; 17:596-603.

30. Weiss B, Widemann BC, Wolters P, Dombi E, Vinks AA, Cantor A, Korf B, Perentesis J, Gutmann DH, Schorry E, Packer R, Fisher MJ. Sirolimus for non-progressive NF1associated plexiform neurofibromas: an NF clinical trials consortium phase II study. Pediatr Blood Cancer. 2014; 61:982-6.

31. Yap YS, McPherson JR, Ong CK, Rozen SG, Teh BT, Lee AS, Callen DF. The NF1 gene revisited - from bench to bedside. Oncotarget. 2014; 5:5873-92. https://doi. org/10.18632/oncotarget.2194.

32. Wood M, Rawe M, Johansson G, Pang S, Soderquist RS, Patel AV, Nelson S, Seibel W, Ratner N, Sanchez Y. Discovery of a small molecule targeting IRA2 deletion in budding yeast and neurofibromin loss in malignant peripheral nerve sheath tumor cells. Mol Cancer Ther. 2011; 10:1740-50.

33. Allaway RJ, Fischer DA, de Abreu FB, Gardner TB, Gordon SR, Barth RJ, Colacchio TA, Wood M, Kacsoh BZ, Bouley SJ, Cui J, Hamilton J, Choi JA, et al. Genomic characterization of patient-derived xenograft models established from fine needle aspirate biopsies of a primary pancreatic ductal adenocarcinoma and from patient-matched metastatic sites. Oncotarget. 2016; 7:17087-102. https://doi. org/10.18632/oncotarget.7718.

34. Rine J. Gene overexpression in studies of Saccharomyces cerevisiae. Methods Enzymol. 1991; 194:239-51.

35. Forsburg SL. The art and design of genetic screens: yeast. Nat Rev Genet. 2001; 2:659-68.

36. Ball CA, Dolinski K, Dwight SS, Harris MA, IsselTarver L, Kasarskis A, Scafe CR, Sherlock G, Binkley G, Jin H, Kaloper M, Orr SD, Schroeder M, et al. Integrating functional genomic information into the Saccharomyces genome database. Nucleic Acids Res. 2000; 28:77-80.

37. Tan JMM, Wong ESP, Kirkpatrick DS, Pletnikova O, Ko HS, Tay SP, Ho MWL, Troncoso J, Gygi SP, Lee MK, Dawson
VL, Dawson TM, Lim KL. Lysine 63-linked ubiquitination promotes the formation and autophagic clearance of protein inclusions associated with neurodegenerative diseases. Hum Mol Genet. 2008; 17:431-9.

38. Nathan JA, Kim HT, Ting L, Gygi SP, Goldberg AL. Why do cellular proteins linked to K63-polyubiquitin chains not associate with proteasomes? EMBO J. 2013; 32:552-65.

39. Komander D, Rape M. The Ubiquitin Code. Annu Rev Biochem. 2012; 81:203-29.

40. Shaid S, Brandts CH, Serve H, Dikic I. Ubiquitination and selective autophagy. Cell Death Differ. 2013; 20:21-30.

41. Ng AC, Baird SD, Screaton RA. Essential role of TID1 in maintaining mitochondrial membrane potential homogeneity and mitochondrial DNA integrity. Mol Cell Biol. 2014; 34:1427-37.

42. Romanoski CE, Che N, Yin F, Mai N, Pouldar D, Civelek M, Pan C, Lee S, Vakili L, Yang WP, Kayne P, Mungrue IN, Araujo JA, et al. Network for activation of human endothelial cells by oxidized phospholipids: a critical role of heme oxygenase 1. Circ Res. 2011; 109:e27-41.

43. Buytaert E, Matroule JY, Durinck S, Close P, Kocanova S, Vandenheede JR, de Witte PA, Piette J, Agostinis P. Molecular effectors and modulators of hypericin-mediated cell death in bladder cancer cells. Oncogene. 2008; 27:1916-29.

44. Bigi A, Beltrami E, Trinei M, Stendardo M, Pelicci PG, Giorgio M. Cyclophilin D counteracts P53-mediated growth arrest and promotes Ras tumorigenesis. Oncogene. 2016; 35:5132-43.

45. Silva GM, Finley D, Vogel C. K63 polyubiquitination is a new modulator of the oxidative stress response. Nat Struct Mol Biol. 2015; 22:116-23.

46. Fujita K, Maeda D, Xiao Q, Srinivasula SM. Nrf2-mediated induction of p62 controls Toll-like receptor-4-driven aggresome-like induced structure formation and autophagic degradation. Proc Natl Acad Sci U S A. 2011; 108:1427-32.

47. Roudebush M, Slabe T, Sundaram V, Hoppel CL, Golubic M, Stacey DW. Neurofibromin Colocalizes with Mitochondria in Cultured Cells. Exp Cell Res. 1997; 236:161-72.

48. Tong JJ, Schriner SE, McCleary D, Day BJ, Wallace DC. Life extension through neurofibromin mitochondrial regulation and antioxidant therapy for neurofibromatosis-1 in Drosophila melanogaster. Nat Genet. 2007; 39:476-85.

49. Masgras I, Ciscato F, Brunati AM, Tibaldi E, Indraccolo S, Curtarello M, Chiara F, Cannino G, Papaleo E, Lambrughi M, Guzzo G, Gambalunga A, Pizzi M, et al. Absence of Neurofibromin Induces an Oncogenic Metabolic Switch via Mitochondrial ERK-Mediated Phosphorylation of the Chaperone TRAP1. Cell Rep. 2017; 18:659-72.

50. Varin J, Poulain L, Hivelin M, Nusbaum P, Hubas A, Laurendeau I, Lantieri L, Wolkenstein P, Vidaud M, Pasmant E, Chapuis N, Parfait B. Dual mTORC1/2 inhibition induces anti-proliferative effect in NF1-associated 
plexiform neurofibroma and malignant peripheral nerve sheath tumor cells. Oncotarget. 2016; 7:35753-67. https:// doi.org/10.18632/oncotarget.7099.

51. Watson AL, Anderson LK, Greeley AD, Keng VW, Rahrmann EP, Halfond AL, Powell NM, Collins MH, Rizvi T, Moertel CL, Ratner N, Largaespada DA. Cotargeting the MAPK and PI3K/AKT/mTOR pathways in two genetically engineered mouse models of schwann cell tumors reduces tumor grade and multiplicity. Oncotarget. 2014; 5:1502-14. https://doi.org/10.18632/oncotarget.1609.

52. Patel AV, Johansson G, Colbert MC, Dasgupta B, Ratner N. Fatty acid synthase is a metabolic oncogene targetable in malignant peripheral nerve sheath tumors. Neuro Oncol. 2015; 17:1599-608.

53. Sheikh TN, Patwardhan PP, Schwartz GK. Abstract 19: Neurofibromatosis type 1 (NF1) status determines sensitivity of soft tissue sarcoma and melanoma cell lines to glutaminase inhibitors. Cancer Res. 2016; 76:19-19.

54. Sheikh TN, Patwardhan PP, Cremers S, Schwartz GK. Abstract 4450: CB839, an orally bioavailable glutaminase inhibitor, shows potent antitumor activity in vitro against models of soft tissue sarcoma and chondrosarcoma. Cancer Res. 2015; 75:4450-4450.

55. De Raedt T, Walton Z, Yecies JL, Li D, Chen Y, Malone CF, Maertens O, Jeong SM, Bronson RT, Lebleu V, Kalluri $\mathrm{R}$, Normant E, Haigis MC, et al. Exploiting cancer cell vulnerabilities to develop a combination therapy for rasdriven tumors. Cancer Cell. 2011; 20:400-13.

56. Shaw AT, Winslow MM, Magendantz M, Ouyang C, Dowdle J, Subramanian A, Lewis TA, Maglathin RL, Tolliday N, Jacks T. Selective killing of K-ras mutant cancer cells by small molecule inducers of oxidative stress. Proc Natl Acad Sci U S A. 2011; 108:8773-8.

57. Zhu Y, Guignard F, Zhao D, Liu L, Burns DK, Mason RP, Messing A, Parada LF. Early inactivation of p53 tumor suppressor gene cooperating with NF1 loss induces malignant astrocytoma. Cancer Cell. 2005; 8:119-30.

58. Hirbe AC, Dahiya S, Friedmann-Morvinski D, Verma IM, Clapp DW, Gutmann DH. Spatially- and temporallycontrolled postnatal p53 knockdown cooperates with embryonic Schwann cell precursor Nfl gene loss to promote malignant peripheral nerve sheath tumor formation.
Oncotarget. 2016; 7:7403-14. https://doi.org/10.18632/ oncotarget. 7232 .

59. Gornostaev L, Lavrikova TI. Transformations of 1-azido2-anthraquinonecarboxylic acid and its esters. Zhurnal Org Khimii. 1984; 20:2208-12.

60. Dwight SS, Balakrishnan R, Christie KR, Costanzo MC, Dolinski K, Engel SR, Feierbach B, Fisk DG, Hirschman J, Hong EL, Issel-Tarver L, Nash RS, Sethuraman A, et al. Saccharomyces genome database: underlying principles and organisation. Brief Bioinform. 2004; 5:9-22.

61. Balakrishnan R, Park J, Karra K, Hitz BC, Binkley G, Hong EL, Sullivan J, Micklem G, Cherry JM. YeastMinean integrated data warehouse for Saccharomyces cerevisiae data as a multipurpose tool-kit. Database (Oxford). 2012; 2012:bar062.

62. Schindelin J, Arganda-Carreras I, Frise E, Kaynig V, Longair M, Pietzsch T, Preibisch S, Rueden C, Saalfeld S, Schmid B, Tinevez JY, White DJ, Hartenstein V, et al. Fiji: an open-source platform for biological-image analysis. Nat Methods. 2012; 9:676-82.

63. Schindelin J, Rueden CT, Hiner MC, Eliceiri KW. The Image J ecosystem: An open platform for biomedical image analysis. Mol Reprod Dev. 2015; 82:518-29.

64. Wright GW, Simon RM. A random variance model for detection of differential gene expression in small microarray experiments. Bioinformatics. 2003; 19:2448-55.

65. Eisen MB, Spellman PT, Brown PO, Botstein D. Cluster analysis and display of genome-wide expression patterns. Proc Natl Acad Sci U S A. 1998; 95:14863-8.

66. Verdoes M, Florea BI, Menendez-Benito V, Maynard CJ, Witte MD, van der Linden WA, van den Nieuwendijk AM, Hofmann T, Berkers CR, van Leeuwen FW, Groothuis TA, Leeuwenburgh MA, Ovaa H, et al. A Fluorescent BroadSpectrum Proteasome Inhibitor for Labeling Proteasomes In Vitro and In Vivo. Chem Biol. 2006; 13:1217-26.

67. Kisselev AF, Goldberg AL. Monitoring Activity and Inhibition of 26S Proteasomes with Fluorogenic Peptide Substrates. Methods Enzymol. 2005; 398:364-78. 